University of South Carolina

Scholar Commons

8-2009

\title{
From Thought to Action in School Mental Health Promotion
}

Mark D. Weist

University of South Carolina - Columbia, weist@mailbox.sc.edu

Follow this and additional works at: https://scholarcommons.sc.edu/psyc_facpub

Part of the Psychology Commons

Publication Info

Published in International Journal of Mental Health Promotion, Volume 11, Issue 3, 2009, pages 32-41.

http://www.ijmhp.co.uk/

(c) 2009 by Clifford Beers Foundation

This Article is brought to you by the Psychology, Department of at Scholar Commons. It has been accepted for inclusion in Faculty Publications by an authorized administrator of Scholar Commons. For more information, please contact digres@mailbox.sc.edu. 
Mark D. Weist

Center for School Mental Health, University of Maryland

School of Medicine, USA

Carl E. Paternite

Center for School-Based Mental Health Programs, Miami University (Ohio), USA

Denise Wheatley-Rowe

Baltimore Mental Health Systems, Inc, USA

Gail Gall

Clinical Assistant Professor, MGH Institute of Health Professions, Charlestown, USA

Keywords: children; adolescents; schools; mental health promotion; policy change

There is a global movement in school mental health promotion that builds on key recognitions that:

- schools are typically under-resourced and supported to promote and address student mental health needs

- young people and families encounter significant barriers to accessing mental health services in specialty settings, typically away from their home and school environments

\section{From Thought to Action} in School Mental Health

\section{Promotion}


programs moving toward the apex of the triangle. There is increasing emphasis on integration of evidence-based strategies and interventions at all points along this public mental health promotion continuum (Schaeffer et al, 2005), and, when done well, SMH promotion is indeed associated with a range of valued outcomes (Stewart Brown, 2006; Weist \& Murray, 2007).

This conference reflects the theme of mental health promotion moving into the mainstream, and this session chronicles programs 'moving from thought to action'. Here, we present three examples that involve moving SMH promotion from thought to action. For each example, we present the key question confronted by program leaders, early responses to this initial question, the growth of the $\mathrm{SMH}$ promotion strategy, current actions, and future directions.

\section{Example 1: In the context of federalism, can one state advance a systematic agenda for SMH promotion?}

In the United States (U.S.), federalism, or states' rights and emphasis on local control of government and its initiatives, may serve as a constraint on policy and program development (Weist et al, 2005). In SMH promotion, this is commonly seen both across states and within states, as one state or locality may be doing a lot in SMH and the neighboring state or locality may be doing little if anything, with limited or no communication between them.

The Ohio Department of Mental Health (ODMH) and the Ohio Department of Education (ODE) have been recognized for their leadership in promoting the mental health and school success of young people through the work of the Ohio Mental Health Network for School Success (OMHNSS, www.omhnss.org). The OMHNSS has an innovative infrastructure of six regional action networks throughout Ohio, each spearheaded by a regional affiliate organization with a strong reputation for effective work related to children's mental health.

The OMHNSS was initially formed in 2001, facilitated by funding to ODMH from the Substance Abuse and Mental Health Services Administration (SAMHSA). Over time, funding for the Network has expanded, and now includes support from ODMH, ODE, and the IDEA Partnership, which is funded by the U.S. Department of Education to provide national leadership in learning supports (see www. sharedwork.org).

Paternite et al (2005) provided a detailed analysis of the early history of OMHNSS, including the chronology of events and steps leading to its inception. They also provided a synopsis of the OMHNSS scope of work during the first four years of its existence, through mid-2005. That synopsis emphasized particularly the OMHNSS Families-Mental Health-Education Shared Agenda Initiative, which involved systematic, grassroots, regional awareness-raising efforts that culminated in a statehouse legislative hearing and a variety of positive follow-up actions and outcomes. In addition, Paternite et al (2005) described initial steps toward expansion of OMHNSS, especially involving development of strong collaborations between the Network's regional affiliate organizations and effective practice partners from six public universities in the state, facilitated by supplementary funding for the Network from SAMHSA.

Throughout its eight-year existence since 2001, OMHNSS has been guided by a clear mission statement and evolving action agenda. Specifically, the mission of the network is:

\section{to help Ohio's schools, community-based agencies, and families work together to achieve improved educational and developmental outcomes for all children-especially those at emotional or behavioral risk and those with mental health problems.}

To accomplish this mission OMHNSS strives:

- to promote awareness of the mental health needs of students attending Ohio's schools and the critical links between mental health and school/academic success

- to promote the adoption and implementation of policies (at all levels) that encourage effective practices to improve the mental health and school success of Ohio's students

- to help to build capacity within mental health and education systems for enhanced collaboration and effective school mental health programs and services

- to build and sustain strong regional action networks to promote mental health-education-family collaborations, with broad stakeholder representation.

The current action agenda for the Network includes the following priorities.

- Through a variety of initiatives, reducing stigma for children and families who need mental health services, to tell the story about the gap between students' mental health needs and the resources available to meet those needs, and to heighten awareness of the critical links between mental health and school success.

- Partnering with regional action networks to enhance 
within-region and statewide collaborative commitment to the Network mission and implementation of the action agenda, actively soliciting and appreciating broad stakeholder input, especially from students and families.

- Encouraging and supporting technical assistance to mental health agencies and schools to improve and expand school mental health services and to promote adoption of effective practices addressing mental health and academic outcomes for students.

- Engaging in targeted special projects, as determined by the membership and sponsoring organizations, to enhance awareness of, and effective programs to address, the mental health and school success of students.

- Serving as a resource to identify and disseminate information about training opportunities, external sources of financial support for school mental health initiatives, and other news pertinent to promotion of the mental health and school success of students.

- Assisting college and university-based professional preparation programs in behavioral health and in education to develop inter-professional strategies and practices for addressing the mental health and school success of Ohio's children. The network promotes and seeks the involvement of families and other non-professionals in these efforts.

Currently, both ODMH and ODE provide direction, offer support, and help to establish long-term goals for the Network, within the framework of its mission and action agenda. A steering team, consisting of OMHNSS regional affiliates, the university-based effective practice partners, family advocates, and representatives from ODMH and ODE, is responsible for providing oversight for OMHNSS activities, setting objectives, serving as a liaison to state agencies, monitoring funding streams, and helping to align the OMHNSS priorities with those of state agencies.

In part, the work of OMHNSS regional affiliates and their regional university-based effective practice partners is guided by priorities that are set within each of the regional action networks. In addition to this ongoing regional work, five Action Teams currently exist to facilitate the statewide work of OMHNSS. Although highlighted below, more detailed information about the work of these Action Teams can be found on the OMHNSS website (www.omhnss.org).

- The Policy Development and Advocacy Action Team focuses on analysis of current policies as they relate to promotion of the mental health and school success of young people, training related to policy development and advocacy, development of recommendations for policy enhancements to promote more effective mental health and educational practices, and awareness-raising events such as statehouse forums.

- The Quality and Effective Practice Action Team works to systematically identify and raise awareness about effective and promising mental health and educational programs and practices in Ohio. Results of this work are showcased on the web-based OMHNSS Effective Practice Registry.

- The Systems Analysis and Change Action Team works to identify the types and extent of school mental health programs and services in place in Ohio's schools, and to promote implementation of effective practices. A recently completed survey with a stratified random sample of school principals about school mental health service delivery is being used as a baseline for assessment of progress in promoting more effective school-based programs and services.

- The School Safety and Violence Prevention Action Team works in conjunction with ODE to implement safety and violence prevention curriculum trainings for teachers. This work emphasizes train-the-trainer workshop programs to school districts, and involves presentation and discussion of a four-module safety and violence prevention curriculum developed jointly by the Ohio Suicide Prevention Foundation and ODE. The curriculum addresses basic information about mental and behavioral health topics including child abuse identification, bullying and violence prevention, substance use and abuse, and depression and suicide. These trainings are being implemented in Ohio to comply with a legal mandate that all teachers in the Ohio workforce receive recurring training on safety and violence prevention.

- The Communication Action Team works closely with the OMHNSS regional affiliates, universitybased effective practice partners, and action team members to ensure that the work of OMHNSS is disseminated broadly and effectively. The Communication Action Team is responsible for maintenance of the OMHNSS website, editorship of the OMHNSS on-line newsletter, publication of OMHNSS Information Briefs on a variety of topics, and development of other pertinent resource materials.

Over the course of its eight-year existence OMHNSS has 
established a strong presence in the state through a wide variety of initiatives resulting in important positive actions and outcomes. Much of this work is summarized in a report titled Shared Agenda Update, on the OMHNSS website (www.units.muohio.edu/csbmhp/resources/resourcessagenda/ OMHNSSSharedAgenda_update_final.pdf). In addition, the results of OMHNSS initiatives are chronicled regularly in issues of the OMHNSS newsletter, available at www.units. muohio.edu/csbmhp/ newsletter.html.

One significant and direct policy impact of OMHNSS work involved an amendment to state legislation regarding standards for educator professional development in Ohio. Specifically, shortly after a 2003 OMHNSS-sponsored legislative hearing, an amendment was added to pending legislation requiring that standards be written into a bill addressing the crucial link between academic achievement and mental health issues. Following passage, this legislation became effective in mid-2004. In addition, more recent bullying prevention legislation aligns very directly with ongoing OMHNSS policy development and advocacy efforts, and with the efforts of other organizations. Specifically, with passage of the legislation in 2008, all elementary school educators in Ohio are required to receive training at least every five years in violence and substance abuse prevention and positive youth development.

\section{Future directions}

Looking to the future, the capacity of OMHNSS to address its mission and evolving action agenda as a statewide network will continue to be influenced by the priorities and levels of grant and contract support provided by its funders. To date, virtually all OMHNSS funding has been year-to-year and subject to the sometimes harsh realities of short-cycle public funding, particularly in very challenging economic times, and especially since OMHNSS is not a direct service provider organization. Nonetheless, OMHNSS continues to work closely with current and anticipated funding partners to effectively ensure the mental health and school success of young people in Ohio.

\section{Example 2: In a highly challenged urban environment, can a city move SMH promotion to scale?}

Baltimore is recognized as a leader in the state of Maryland and in the nation for its long history of providing Expanded School Mental Health (ESMH) services to its public school students (Flaherty \& Weist, 1999). Both the public mental health and the education systems in Baltimore City have long recognized the need to collaborate and provide the opportunity for broad-scale mental health interventions that will advance the academic achievement goals of the educational system via promotion of students' mental and social-emotional well-being (Walrath et al, 2004). The term 'Expanded School Mental Health' in this context is used to convey a shared school-family-community system agenda to build a full continuum of mental health promotion for students and their families in general and special education, where these 'expanded' services build on those provided by school employees and school systems (Weist, 1997).

Early development of ESMH in Baltimore started with four schools connected to school-based health centers in 1989. These schools served as examples of the promise of integrating more comprehensive mental health promotion in schools, and also highlighted significant unmet needs, as mental health services quickly became the number one reason for student referral to the health centers (Flaherty \& Weist, 1999). Progressively, leaders from child-serving systems (as above) began to work more closely together in purposefully building an ESMH initiative. By 1993, there were ESMH services in 32 Baltimore schools, 79 by 1999 , 84 by 2003 , and 105 in the current 2008-09 school year, which represents over $50 \%$ of the city's roughly 190 schools.

ESMH services have gained widespread support by offering opportunities for both prevention and direct intervention, and by mitigating additional barriers posed by transportation issues, lack of insurance and stigma. Currently, 42 elementary schools, 41 middle/k-8 schools, and 22 high schools are offering ESMH services. These services are available to any student in need and are focused primarily on students enrolled in general education programs, providing a resource for early identification, and intervention prior to onset of more serious debilitating problems develop. (Please note that the city has a well-developed system of mental health supports for students in special education, provided by school-employed mental health professionals.) Through creative partnership agreements with 12 community-based programs, mental health clinicians are employed to work on-site in schools.

The success of the historic collaboration between the local mental health authority and the educational system in Baltimore City can be attributed largely to development of a common vision supported by braided funding from key stakeholder groups. The existing infrastructure for ESMH services relies on several different funding streams to finance prevention services that are supported by the total contracted amount of approximately $\$ 3.1$ million to community-based mental health programs (Figure 1, overleaf). 


\section{FIGURE 1 Expanded School Mental Health Services Funding Sources in Baltimore City}
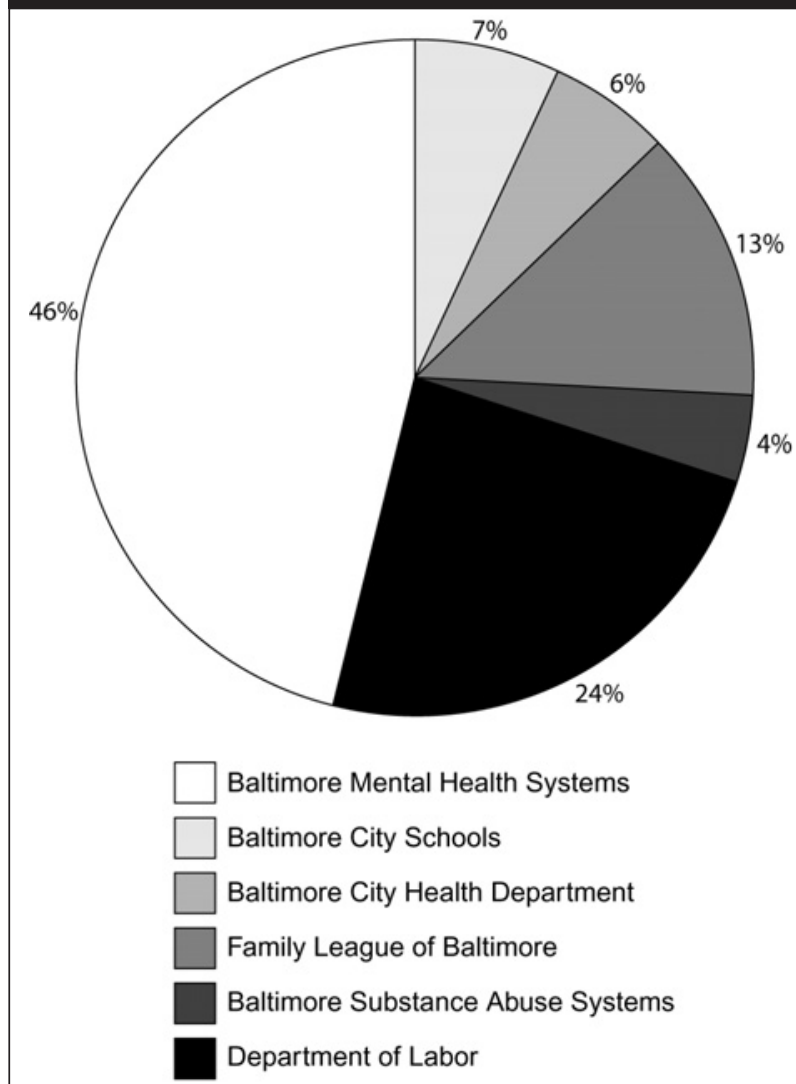

- Baltimore Mental Health Systems, Inc. (BMHS). BMHS is the core service agency for the Public Mental Health System in Baltimore City and contributes $24 \%$ to the total overall budget.

- Baltimore City Schools (BCS) contributes $46 \%$ to the total budget.

- Baltimore City Health Department contributes seven per cent to the total budget.

- Family League of Baltimore, Inc. (FLBC) is the local management board in this jurisdiction and contributes six per cent to the total budget.

- Baltimore Substance Abuse Systems, Inc. (BSAS) is the local substance abuse authority and most recent funder to join the collaborative partnership, and contributes $13 \%$ to the total budget.

- Department of Labor contributes four per cent to the total budget.

Additionally, the Medicaid-funded Public Mental Health System fee-for-service reimbursement is accessed by community-based mental health programs for treatment services delivered to students who meet the criteria for a formal psychiatric diagnosis. This array of diverse funding sources helps provide stability and support for the continuum of ESMH services.

The implementation of ESMH services has been guided by constant discussions and interactions with leaders from Baltimore City Schools, BMHS, schools, the communitybased programs, and community stakeholders, especially families and young people. These discussions over time have led to progressive, organic evolution of these services. Early in the school year 2005-2006, the network of ESMH providers agreed that the increased visibility and growth of these services necessitated more formal strategic planning and guidance. These systems, the University of Maryland Center for School Mental Health (CSMH), and the city Commissioner of Health worked together to develop this strategic plan and corresponding document, Baltimore City Expanded School Mental Health Programs: Findings and Recommendations (Sharfstein, 2006). Key components of the strategic plan include:

- development of a 'Standards' model (Table 1, opposite) addressing how services are organized, staffed, funded, and coordinated with communitybased programs - these Standards were adopted by every participating provider agency

- creation of a consistent funding process, with a goal of two thirds contractual funding for promotion and prevention services (not fundable through the traditional fee-for-service mechanism)

- an application process by schools and community mental health agencies working together, with strong family input, to receive contracts for services and to address key issues such as tailoring services to address school needs and strengths, emphasizing evidence-based practices, and participating in common training, quality assessment, and improvement and evaluation processes.

Implementation of the above components was initiated in preparation for the 2007-08 school year. All key stakeholder groups were invited to participate in shared decision-making through membership of the ESMH Advisory Committee. This committee, co-chaired by leadership from both Baltimore City Schools and BMHS, includes representatives of the Baltimore City Health Department, the University of Maryland CSMH, the Johns Hopkins University Center for Prevention of Youth Violence, the Family League of Baltimore City, parent and family advocacy groups, local foundation leaders, mental health agencies, community members, and school principals. This committee provides guidance to support additional efforts to improve and 
TABLE 1 ESMH 'Standards': The Mental Health Professional is Expected to Provide or Participate in the Following Services and Activities According to the Delineated Staffing Level

LEVEL OF STAFFING IN FULL-TIME EQUIVALENT (FTE)

0.5

1.0

Total hours per week

20

40

A. School-wide supportive activities $=20 \%$

$4 \mathrm{~h} / \mathrm{wk}$

$8 \mathrm{~h} / \mathrm{wk}$

- Total number of school staff/teacher consultations for the year

- Number of school teams/committee meetings attended for the year

- Total number of in-service presentations for school staff for the year

- Attendance at school functions

- School-wide crisis response

- Participation in school wide behavior management

B: Treatment services $=\mathbf{5 0} \%$

$10 \mathrm{~h} / \mathrm{wk}$

$20 \mathrm{~h} / \mathrm{wk}$

Average number of students engaged in treatment services per week

- Screening/assessment/evaluation/treatment planning

- Treatment services

- Crisis response

- Family contacts

- Teacher consultation

- Clinical documentation

- Reimbursement activities

\section{C: Group prevention activities $=\mathbf{2 0} \%$}

$4 \mathrm{~h} / \mathrm{wk}$

8 h/wk

Total number of group prevention activities/groups provided for the year

- Small student group prevention activities

- Classroom-wide prevention activities

- School-wide prevention activities/assemblies

- Parent/family focused group prevention activities

- Documentation/record of group prevention activities

D: Professional Development Activities = $10 \%$

2 h/wk

4 h/wk

- BMHS and other educational activities

- Agency meetings and trainings

- Supervision

evaluate the evolution of ESMH services. As an example, these groups have come together to develop a behavioral health initiative to support high-risk students in the sixth grade in 37 schools, using a promising multimedia approach to enhance student attendance and reduce their involvement in risk behaviors.

\section{Future directions}

The progressive expansion of ESMH programs in Baltimore's schools, from four in 1989 to 105 in 2009, has been supported by a growing coalition of young people, families, schools, community systems, and leading community agencies and advocates. There is much passion in all these groups for further expansion of the network, ultimately to reach all 190 schools in the city. Current plans for future growth emphasize building program evaluation toward a more comprehensive evaluation strategy to be implemented consistently in all 105 schools, and to consider program fidelity and impacts on outcomes valued by families and schools. The evaluation plan, developed by university researchers and national leaders in child and adolescent mental health, assesses ESMH impacts in key realms including school behavior, attendance, classroom functioning, psychosocial adjustment, and academic outcomes for groups of students receiving ESMH services. The hope is that findings from this comprehensive evaluation, completed in the current 2008-09 school year, will provide additional fuel for advocacy efforts to expand the ESMH funding base beyond its current $\$ 3$ million to grow in progressively more city schools. In addition, the Baltimore experience in ESMH is being shared with other jurisdictions in Maryland, as a formal and well-structured plan for building school mental health promotion.

\section{Example 3: Can a free and easy-to-use measure of quality assessment and improvement in SMH be developed and become highly used?}

In the early 2000s, the University of Maryland CSMH, through a research process, developed the School Mental Health Quality Assessment Questionnaire (SMHQAQ), a 40-item measure of quality assessment and improvement (QAI) to be completed by SMH teams to evaluate and 
improve the quality of school mental health promotion services (Weist, Sander et al, 2005). The CSMH worked closely with the National Assembly on School-Based Health Care (NASBHC) to adapt the SMHQAQ to be directly applicable to staff working in school-based health centers (SBHCs), leading to the development of the Mental Health Planning and Evaluation Template (MHPET). The MHPET has been refined intensively since its initial development in 2003, and now includes 34 items that are generally relevant to QAI planning and action in SMH. The tool is now an online and free resource (see www. nasbhc.org, under 'Mental Health' and 'MHPET') that has been completed by staff from more than 75 schools in seven U.S. states. ${ }^{1}$

To use the tool, a team leader provides brief background information on the school on the website, then asks other staff from the school, and staff from collaborating community mental health agencies, and advocates (as always, ideally to include families and youth) to go online and complete the measure, reflecting their views on the school's mental health promotion efforts for each of the 34 items, using a 1-6 Likert rating from 'not at all' to 'fully in place'. Online, real-time scoring of the measure for the school team is then provided, with averages computed for each item and items scored less than 3, which are potential targets for QAI planning and action. Using this process, the team would, ideally, pick a few items to focus on over the course of the school year and meet regularly to gauge progress and to adjust and improve QAI plans. The MHPET would be completed again, say at the beginning of the next school year, to assess progress (Weist et al, 2007).

Here we provide an example of the strategic use of MHPET to advance the SMH agenda by one U.S. state Massachusetts (MA). In 2006, the MA Legislature created funding for 2007 and 2008 to improve access to mental health and substance abuse services in schools by building the capacity of SBHCs. With this new funding, the Department of Public Health designed an initiative to improve the scope and quality of mental health and substance abuse services in SBHCs. Five SBHCs were selected as pilot sites through a competitive process, and the MA Coalition of School-Based Health Centers was selected to evaluate their efforts. Pilot sites were located in urban areas with high populations of immigrant and refugee students and high rates of poverty, and all had graduation rates well below the state average of $80.9 \%$.

The funds were released in April of 2007 and the grantees

${ }^{1}$ Dimensions and indicators for the MH-PET were developed by a workgroup commissioned by NASBHC and including members TJ Cosgrove, Missy Fleming, Linda Juszczak, Julia Lear, Chris Reif, John Schlitt, Deidre Washington, and Mark Weist, with consultation provided by Steve Adelsheim. had three main goals for service delivery.

- Develop the capacity of primary care clinicians to:

$\square$ identify and use screening tools for substance abuse and depression

$\square$ identify how to conduct further assessment for students at risk.

- Recruit and arrange for supervision for mental health clinicians to:

$\square$ work in the school environment

$\square$ understand the challenges and constraints of practicing as a 'guest of the school'.

- Develop systems of documenting cases identified, tracking referrals, and ensuring follow up and care coordination.

Participating SBHCs quickly moved to expand their mental health services through a variety of methods: expanding the hours of existing clinicians, recruiting new staff, adding prevention services, adding case management, increasing consultation time with child psychiatrists, and supporting additional clinical training for primary care nurse practitioners in psychopharmacology.

The evaluation had three main goals:

- Develop a continuous quality assessment and improvement program using the MHPET

$\square$ implement the Mental Health Planning and Evaluation Tool (MH-PET)

$\square$ collaborate with NASBHC in the analysis of MHPET findings and provision of technical assistance to sites

$\square$ collaborate with SBHC to select target indicators, measures, and processes for improvement.

- Convene and support a Community of Practice $(\mathrm{CoP})$ including key stakeholders to share expertise in SMH services delivery and document best practices identified.

- Report and disseminate findings.

In the Spring of 2007, staff and leaders from the participating SBHCs were brought together for a training and networking session on effective SMH and use of the MHPET, and including key leaders involved in the development of the tool. In addition, at each school site visits were conducted that included structured interviews with SBHC primary care providers, social workers, school nurses, school counselors, and school administrators. The combination of bringing experts in the field to the $\mathrm{CoP}$, ascertaining background information about the mental health climate of each school, 
and using a validated instrument (MHPET) converted a diverse group of SBHC into stakeholders in the improvement process. Each SBHC team finalized the year by identifying the target goals and explaining to their $\mathrm{CoP}$ colleagues their rationale for the choice and expectations for achieving improvements.

Each pilot site selected target indicators, measures, and processes for improvement. Three dimensions of service delivery were identified by the five pilot sites as areas for improvement: stakeholder involvement, school collaboration and coordination, and quality assessment and improvement. Throughout the following academic year, staff from each SBHC worked on their improvement goals and reported their progress through monthly CoP meetings. Examples of improvement strategies are highlighted in Tables 2-4, below.

In general, having a systematic strategy to evaluate and guide SMH services in these school-based health centers offered many advantages, including raising awareness of dimensions of school mental health, building teams and cohesion among them, and providing direction for program improvement. There were also challenges experienced in this process, including ongoing struggles with securing and maintaining funding and for organizational commitment to the concept of quality, prioritizing relationships and adjusting to the reality of relationship development (which in some cases took years), and assuring consistent emphasis on continuous engagement with young people and families, and school and community stakeholders. With regard to increased stakeholder involvement, programs encountered a number of realities, including no funding and limited historical precedent for this work, negotiating release time to interact with stakeholders, and recognizing the need for enhanced training in cultural competence.

Using the MHPET as a guideline continued to give each school a framework for improvement targets and activities. A second MHPET evaluation was conducted in the Spring of 2008. By June of 2008, the issues in school collaboration had been examined thoroughly from the perspective of the five grantees. Successes included increased referrals from school staff, increased participation by faculty in SBHC advisory boards, and softening of some of the barriers between the SBHC behavioral health staff and school administrators. In all but one school, demand for services increased from both faculty and school staff, so that most had a waiting list for services by mid-year and began to work on managing the caseload, from decreasing 'no shows' to monitoring acuity and increasing access to psychopharmacology assessments. The grantees shared techniques for maintaining student confidentiality when concerned teachers wanted to know what had happened as a result of referrals, how to get parents involved, and how to be effective in de-escalating reactive situations between students and school staff.

\section{Future directions}

The use of the MHPET as a systematic strategy for QAI, combined with the development of a Community of Practice (CoP; Wenger et al, 2002), has proven successful in bringing diverse schools together, identifying and overcoming barriers, and building best practices in SMH in these school-based

\section{TABLE 2 Stakeholder Involvement}

With students

With families

With community agencies
- Updated 'Teen Help' Cards and brochures on youth services with sponsoring agency

- Youth focus groups on services wanted

- Youth Health Council

- Inclusion on SBHC Advisory Committee

- Activities and programs that target specific groups of students

- Working with local youth task force

- Parent focus groups on access to care

- Family Academy for parents

- Inclusion on SBHC Advisory Committee

- Presentations at Parent Nights

- Individual meetings for specific student problems

- Family Arts Night

- Partnership with local health department

- Collaboration with DSS and sheriff's department

- Collaborations with Girls Inc., Big Brother/Big Sisters, community teen programs, and YMCA

- Meeting with legislators and SBHC Advocacy Day

- Youth Task Force 


\section{TABLE 3 School Collaboration and Coordination}

Increasing communications between school and SBHC staff:

Identifying champions of SBHC within the school and working with a broad range of staff including:

: Peer mediator coordinators

- School security staff

Providing training to both SBHC and school staff that is convenient and offers credit for professional development:
- School drop-out prevention coordinator

- School adjustment counselors and social workers

- Advisory council meetings

Student support meetings

Weekly guidance team meetings

- School nurse meetings

- After-school dialogues about behavioral issues

Teacher appreciation days

- Confidentiality

- Substance abuse (tobacco, alcohol, and drugs)

- Violence issues including domestic, dating, and bullying

- Offering Critical Incident Stress Debriefings to school administration

- Annual SBHC Advisory Council Retreat

\section{TABLE 4 Quality Assessment and Improvement}

Involving stakeholders in program development
- Provide professional development for clinicians by supporting attendance at national meetings

- Promote innovation among staff for identifying needs and designing quality improvement measures

- Include a school administrator actively in CoP and school meetings

- Reward interested and capable staff with increased funding for work on CQAI projects based on interest and capacity rather than professional title

- Include young people and parents in SBHC and health-related activities by partnering with other programs in the sponsoring agency or other agencies health centers. The SBHC administrators and staff report feeling more effective in delivering services and in involving stakeholders, acknowledging that the latter should be an ongoing priority. Quality assessment and improvement have moved from an exotic foreign language to the vernacular. Many more students have been screened and referred, and have received mental health services because of the initiative, and the quality of the services has steadily improved.

An important lesson of this project is that the concept of quality in school mental health services is challenging. For example, it demands collaboration not only between providers, consumers, and funders, but also between stakeholders with very diverse, and sometimes competing, agendas. Successful implementation of QAI programs requires financing, leadership across the program and at each site, development of a common language, and time for each school team to learn how best to work together. Addressing these themes, and ongoing use of QAI as in the MHPET, are now priorities in SBHCs in Massachusetts, with the goal of expanding high-quality SMH throughout the state.

\section{Conclusion}

These three examples highlight movement from initial ideas to action to programmatic and policy influence and growth of school mental health promotion efforts. What is happening in these two states and one city in the U.S. is mirrored in the global development of SMH promotion, with many developments fueling the growth and impact of this emerging field, as in this conference and its theme of Moving Mental Health and Wellness Promotion into the Mainstream (Toronto, March 4-6, 2009, www.cliffordbeersfoundation.co.uk/ toronto.htm). Indeed, within child and adolescent-serving systems, systems of education are usually the largest, and represent the mainstream for mental health promotion and intervention as the most universal natural setting for children and adolescents (and for a large proportion of adults).

This recognition, combined with the recognition that, when done well, SMH promotion has the potential to improve outcomes valued by families and schools, is helping to spur its global development, with many opportunities for involvement. They include joining global networks such as the Movement for Global Mental Health, presented on at this 
conference by Dr Vikram Patel (www.globalmentalhealth. org), the International Alliance for Child and Adolescent Mental Health and Schools (www.intercamhs.org), and the Global Consortium for the Advancement of Promotion and Prevention in Mental Health (www.gcappmentalhealth.org). Streams of presentations on school mental health promotion and opportunities for networking will be available at upcoming conferences, including the 14th Annual Conference on Advancing School Mental Health (Minneapolis, US; November 2-4, 2009, see http://csmh.umaryland.edu), the 20th IUHPE World Conference on Health Promotion (Geneva, Switzerland; July 11-15, 2010, see www.iuhpe.org), and the 6th World Conference on the Promotion of Mental Health and the Prevention of Mental and Behavioural Disorders (Washington DC US; November, 2010, see www.cliffordbeersfoundation.co.uk). Finally, in the past two years two new journals reflecting the interdisciplinary SMH promotion field were launched, Advances in School Mental Health Promotion (www.schoolmentalhealth.co.uk) and School Mental Health (www.springer.com). There is no better time for involvement in school mental health promotion than now.

\section{Acknowledgement}

Support for writing this article was provided by cooperative agreement U45 MC 00174-10-0 from the Office of Adolescent Health, Maternal and Child Health Bureau (Title V, Social Security Act), Health Resources and Services Administration.

\section{Address for correspondence}

Mark D. Weist, Ph.D., Professor and Director, Center for School Mental Health, Division of Child and Adolescent Psychiatry, University of Maryland School of Medicine, 737 West Lombard Street, 4th Floor, Baltimore, MD 21201, USA. email: mweist@psych.umaryland.edu; website: http//csmh.umaryland.edu.

\section{References}

Flaherty LT \& Weist MD (1999) School-based mental health services: the Baltimore models. Psychology in the Schools $36379-89$.

Paternite CE, Flaspohler P \& Rietz K (2005) Promotion of effective school mental health programs and services in Ohio. Report on Emotional and Behavioral Disorders in Youth 5 (3) 65-6 69-72.

Power TJ (2003) Promoting children's mental health: reform through interdisciplinary and community partnerships. School Psychology Review 32 (1) 3-16.

Schaeffer CM, Bruns E, Weist M et al (2005) Overcoming challenges to using evidence-based interventions in schools. Journal of Youth and Adolescence 34 (1) 15-22.

Sharfstein J (2006) Baltimore City Expanded School Mental Health Programs Findings and Recommendations. Baltimore City Health Department Publication, USA.

Stewart-Brown S (2006, accessed 11th June 2007) What is the evidence on school health promotion in improving health or preventing disease and, specifically, what is the effectiveness of the health promoting schools approach? World Health Organization Regional Office for Europe's Health Evidence Network. Health Evidence Network Report: www.euro.who.int/document/e88185.pdf.

Walrath C, Bruns EJ, Anderson KL, Siegel MG \& Weist MD (2004) Understanding expanded school mental health services in Baltimore City. Behavior Modification 28 472-90.

Weist MD (1997) Expanded school mental health services: a national movement in progress. In: TH Ollendick \& RJ Prinz (Eds) Advances in Clinical Child Psychology, Volume 19. New York, USA: Plenum Press.

Weist MD \& Murray M (2007) Advancing school mental health promotion globally. Advances in School Mental Health Promotion Inaugural Issue 2-12.

Weist MD, Paternite CE \& Adelsheim S (2005) SchoolBased Mental Health Services. Report to the Institute of Medicine, Board on Health Care Services, Crossing the Quality Chasm: Adaptation to Mental Health and Addictive Disorders Committee. Washington, DC, USA: Institute of Medicine.

Weist MD, Sander MA, Walrath C et al (2005) Developing principles for best practice in expanded school mental health. Journal of Youth and Adolescence 34 (1) 7-13.

Weist MD, Stephan S, Lever N et al (2007) Quality and school mental health. In: S Evans, M Weist \& Z Serpell (Eds) Advances in School-Based Mental Health Interventions. New York, USA: Civic Research Institute.

Wenger E, McDermott R \& Snyder WM (2002) Cultivating Communities of Practice: A guide to managing knowledge. Boston, USA: Harvard Business School Press. 